\title{
Applied Research on the Construction of Pastoral Complex under the Creative Agriculture Model
}

\author{
Chen Juanjuan \\ Chongqing Technology and Business Institute Chongqing 400052
}

Keywords: Creative agriculture model; pastoral complex; meaning

\begin{abstract}
The creative agriculture model is an important guide for rural social and economic development in China in the new era. It is also an important foundation for promoting beautiful rural construction and promoting agricultural transformation and upgrading. Under the construction of the creative agriculture model, the construction of rural complex is to stand in a new historical period, plan a new pattern of rural economic development and let the construction of beautiful villages be implemented. Based on the creative agriculture model, this paper analyzes the construction significance of the rural complex and on this basis, from the three aspects of exploring the new model of rural and rural complex, excavating and constructing local culture and closely fighting poverty, it elaborates the realization strategy of rural complex under the construction of agricultural model.
\end{abstract}

\section{Introduction}

In February 2017, the No. 1 Document of the Central Committee put forward the concept of "idoral complex" as a new model for the development of rural economic construction. The creative agriculture model is oriented towards solving the "three rural issues" and promotes the new construction of rural economic and social development through the construction of beautiful countryside $^{[1]}$. Under the creative agriculture model, the construction of rural complex can proceed from reality and grasp the current situation of China's agricultural economic development, in order to cultivate new formats and promote the development of rural ecological civilization. In recent years, relying on the development of characteristic towns and creative cultural industries to carry out the construction of rural complexes has formed a great effect on promoting regional agricultural economic development. Based on the study of the pastoral complex, this paper elaborates on how to accelerate the construction of the rural complex in the mode of creative agriculture.

\section{The realization significance of rural rural complex under the construction of creative agriculture model}

The creative agriculture model is oriented towards solving the three rural issues and through the transformation and development of the agricultural economy, it promotes the upgrading of rural tourism and the reform of the agricultural supply side structure. Guided by the creative agriculture model, we will actively promote the construction of rural and rural complexes and further integrate rural ecological resources to achieve multi-industry integration and development in the fields of cultural industry, leisure tourism, processing and manufacturing. Therefore, the realization of rural rural complex under the construction of creative agriculture model can revitalize rural social and economic development with new development thinking and new development concepts and help urban and rural overall reform. Specifically, the realization of the rural rural complex under the creative agriculture model is mainly in the following aspects ${ }^{[2]}$. The realization significance of the rural rural complex under the construction of creative agriculture model is shown in Figure 1. 

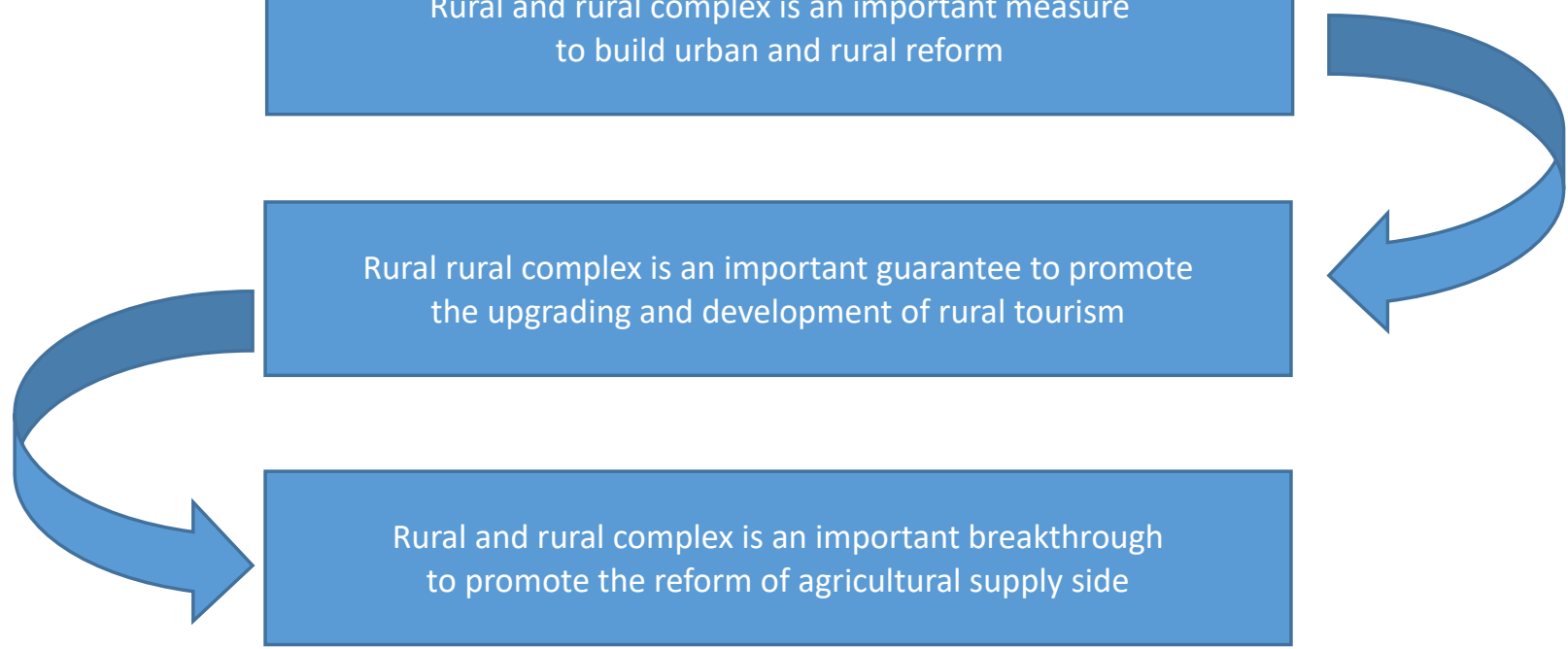

Figure 1: realization significance of the rural rural complex under the construction of creative agriculture model

\subsection{Rural and rural complex is an important measure to build urban and rural reform}

Deepening urban and rural overall reform is the inherent demand of China's social and economic development in the new era and it is also an important foundation for building a socialist agricultural economic system with Chinese characteristics. The construction of rural rural complex can realize the effective integration of rural multi-functional, relying on leisure function, industrial function and cultural function to provide a good platform for urban and rural development. At present, China's rural social economy is in a stage of rapid development. By accelerating urban and rural overall reform, it can provide more infrastructure construction and public service resources for rural social and economic development. Therefore, from the perspective of reform and development, the construction of rural rural complexes can root rural social and economic development and promote urban and rural integrated reform by optimizing the environment, building resources and strengthening governance.

\subsection{Rural rural complex is an important guarantee to promote the upgrading and development of rural tourism}

Transformation and upgrading is an important direction of the current rural economic development and an important part of building a new agricultural economic model of ecology and tourism. Rural ecological resources are abundant and the construction of rural complexes can integrate superior resources and create more economical tourism culture industries by developing creative agriculture and recycling agriculture. The construction of rural rural complex will enlarge and integrate rural ecological resources and promote the upgrading of rural tourism under the "creative + ecological" agricultural model, so that the new rural tourism mode will become an important part of promoting rural economic development and building rural ecological civilization. Grasp the hand. Therefore, the construction of rural rural complexes has promoted the development of new rural formats and is an important guarantee for promoting the upgrading and development of rural tourism in the new era ${ }^{[3]}$.

\subsection{Rural and rural complex is an important breakthrough to promote the reform of agricultural supply side}

The idyllic complex is a new type of agriculture that integrates ecology, industry and culture and plays an important role in promoting the reform of the supply side of agriculture. First of all, the idyllic complex focuses on "creative agriculture + recycling agriculture + tourism experience" and emphasizes the establishment of a characteristic agricultural industrial economic belt. This has provided an entry point for regional agricultural supply-side reforms and revitalized the vitality of 
agricultural economic development. Secondly, the multi-industrial status of the rural complex has become an important carrier for promoting rural poverty alleviation and realizing rural revitalization. To create a new development pattern of "people's wealth and ecological beauty", "characteristic agriculture + entrepreneurial agriculture" makes the characteristics more prominent and makes creativity a bright spot. This is an important way to further consolidate the rural economic development and accelerate the reform of the supply side of agriculture ${ }^{[4]}$.

\section{The realization strategy of rural rural complex under the construction of creative agriculture model}

The creative agriculture model is an important measure for the party and the country to stand at the new height of history in the new era and comprehensively deepen the construction of the "three rural". The countryside is rich in ecological resources and local culture. The construction of these elements is an important foundation for the construction of rural complexes. Through the close integration of characteristic town construction, local culture excavation and fighting against poverty, it has greatly promoted the effective landing of the rural complex in rural economic construction. In the author's view, the construction of the rural complex should be based on reality, closely linked to the current situation of rural economic development, based on characteristic agriculture and vigorously build a rural complex such as leisure tourism, cultural creativity and promote rural social and economic development. Therefore, in particular, the construction of the rural complex can be carried out from the following aspects ${ }^{[5]}$.

\subsection{Taking the construction of characteristic towns as a carrier to explore a new model of rural and rural complex}

In the construction of beautiful countryside, the rural complex has been practiced and the construction of characteristic towns further integrates the rural complex into the rural economic development and construction in a more specific form. First of all, based on the construction of characteristic towns, under the active cultivation of characteristic industries, the rural economic vitality will be revitalized, the rural economic resources will be better integrated into the new business mode and a more colorful industrial model will be realized to achieve better agricultural economic development.

\subsection{Relying on the inheritance of local culture, strengthening the excavation and construction of local culture}

Culture is an important part of rural social economy. In the construction of rural complex, it should rely on the excavation and inheritance of local culture to make the idyllic complex richer and become the business card of the famous village. In the traditional rural economic construction, the lack of local culture has led to the "deformation" of rural social and economic development. To this end, the construction of the rural complex under the creative agriculture model should fully rely on the local culture to create a new model of cultural industry with a local culture, in order to better revitalize the development of rural economic construction. At present, there are 252 and 276 historical towns and famous villages in China. In the joint construction of towns and villages, the cultural elements of famous towns and famous villages are excavated and the construction of rural and rural complexes is promoted by cultural and creative development. The weight of each relevant factor is shown in Table 1.

Table 1: Training impact weights

\begin{tabular}{|c|c|c|c|}
\hline Index & Mode & Skill & Equipment \\
\hline Weight & 0.1465 & 0.4224 & 0.4411 \\
\hline
\end{tabular}

\subsection{Guided by the fight against poverty, the organic combination of fighting against poverty}

Whether it is the construction of beautiful countryside or the development of rural complex, it is 
guided by the development of rural economy and promotes the realization of the creative agriculture model. In the construction of the idyllic complex, it should be guided by the fight against poverty, develop the characteristic agricultural industrial economy, promote the development of the rural economy and solve the problems of people's income-generating difficulties. Rural ecological resources are idle, lack of development and the effective use of resources can stimulate the development of global agricultural economy.

\section{Conclusion}

All in all, the creative agriculture model is an important guiding ideology for the Party Central Committee to stand at a new height in history and to plan the construction of China's "three rural". Once the rural community complex was put forward, it quickly became an important carrier for the development of agricultural economy in various places. Guided by the creative agriculture model, through the construction of characteristic cultural towns and modern farms, we will actively explore the model of the pastoral complex in the new era and create better conditions for the rural complex to better move towards rural economic development. The local culture is an important part of the rural social economy. In the collective development, the rural complex should strengthen the excavation and construction of the local culture and rely on the local culture to build an idyllic complex with a local culture. The fight against poverty is the foundation of the creative agriculture model. The rural and rural complex should be closely integrated with poverty alleviation and reform and the new business and new industries of the rural complex should promote the development of the rural economy and achieve a comprehensive well-off society.

\section{References}

[1] Agriculture - Agribusiness; New Findings from University of Putra Malaysia in Agribusiness Provides New Insights (Additional additives to reduce ash related operation problems of solid biofuel from oil palm biomass upon combustion)[J]. Biotech Week,2018.

[2] Danilo Russo,Luciano Bosso,Leonardo Ancillotto. Novel perspectives on bat insectivory highlight the value of this ecosystem service in farmland: Research frontiers and management implications[J]. Agriculture, Ecosystems and Environment,2018,266.

[3] Thiago Ferreira Rodrigues,Adriano Garcia Chiarello. Native forests within and outside protected areas are key for nine-banded armadillo ( Dasypus novemcinctus) occupancy in agricultural landscapes[J]. Agriculture, Ecosystems and Environment,2018,266.

[4] Ersilia D'Ambrosio,Anna Maria De Girolamo,Maria Cristina Rulli. Assessing sustainability of agriculture through water footprint analysis and in-stream monitoring activities[J]. Journal of Cleaner Production,2018,200.

[5] F.M. Liben,C.S. Wortmann,H. Yang,J.L. Lindquist,T. Tadesse,D. Wegary. Crop model and weather data generation evaluation for conservation agriculture in Ethiopia[J]. Field Crops Research,2018,228. 